\title{
Measuring Information Searching Competence
}

\section{Leon A. Jakobovits and Diane Nahl-Jakobovits}

\begin{abstract}
A taxonomy of instructional objectives for search behavior was used to develop a quiz that measures skills in three domains of search behavior (affective, cognitive, sensorimotor) at three levels of competence (basic, intermediate, advanced). A computer-based education system known as PLATO was used to test an online interactive measure of information searching competence on three populations of university students $(n=69)$. A rationale is presented for measuring these three domains of search behavior by means of three corresponding types of quiz items (true/false, multiple choice, and fill-in). Implications for bibliographic instruction are explored, including the desirability of tailoring teaching activities to build up three corresponding types of memory for search behavior: affective memory, cognitive memory, and sensorimotor memory.
\end{abstract}

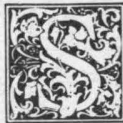

tatements of instructional objectives for bibliographic instruction usually have included only cognitive items. ${ }^{1}$ Recent trends in instruction have recognized that teaching and learning involve the three traditional domains of human affairs: affective for feelings, and attitudes; cognitive for knowledge and reasoning; and sensorimotor for perception and action. ${ }^{2}$ There is an increasing awareness in librarianship of the advantage in considering all three domains of behavior when organizing activities for users, as exemplified at a Maryland public library where toys in the collection are categorized according to the major areas of child development in the three domains. ${ }^{3}$ A handbook on teaching library instruction includes instructional objectives in the three domains. ${ }^{4}$ The categories "feelings, thoughts, and actions" are used in a study on the stages students go through in the library research process. ${ }^{5}$ A library resource workbook was revised to include exercises designed to impart skills in all three domains. ${ }^{6}$ Similarly, our intention was to develop a balanced curriculum for information searching competence for university students, making certain that all three domains were adequately represented.

\section{TAXONOMY OF INFORMATION SEARCHING COMPETENCE}

From the behavioral perspective, searching is a threefold activity. The searcher first feels an information need or motive, then plans a seek-and-find strategy, and finally, executes it. Information needs provide the motive power for searching behavior. Planning and decision making provide the means by which a need can be fulfilled through performing an activity. This activity is goal-directed (integrated), which means that the motive or goal continuously governs the selection of steps to be executed. The goal contains a definition of what the last step ought to be. Blocks to achieving success in this ultimate step are also solved under the guidance of the ruling objective or goal. These distinctions represent three traditional domains of human endeavor: the affective (needs, motives), the cognitive (thoughts, images), and the sensorimotor (sensations, movements).

Leon A. Jakobovits is a Professor in the Department of Psychology and Diane Nahl-Jakobovits is an Instructor in the School of Library and Information Studies at the University of Hawaii, Manoa. 
A threeway perspective on library behavior was recently proposed as a taxonomy of search skills. ${ }^{7}$ Table 1 summarizes the taxonomy. Following the work of Benjamin Bloom and associates on educational objectives, all possible search activities that users can perform in a library are automatically defined as separate skills. Three types of skills in human behavior are affective skills (corresponding to feelings and motives), cognitive skills (corresponding to thoughts and plans), and sensorimotor skills (corresponding to perceptions and motor acts). Three stages of learning library skills within each of these three behavioral domains are depicted in table 1 . The nine cells or categories from a matrix for localizing particular library skills according to behavioral domain and level of expertise.

A searcher's persistent attraction to learning the information searching pro- cess and striving to improve are "affective skills." A searcher's abilities to develop effective plans and make valid decisions are "cognitive skills." A searcher's acuity in visual identification and prowess in maneuvering in dynamic information environments are "sensorimotor skills." Three levels of skills acquisition exist within each of the three behavioral domains. The nine categories represent different and independent aspects of the complex behavior of learning to become a competent searcher. For example, category [A1] (Affective domain, Level 1) is titled Affective Orientation and is defined as "demonstrating willingness to practice library tasks, and maintaining selective attention (= library adjustment versus library maladjustment)." Category [C2] Cognitive domain, level 2) is titled, Cognitive Interaction and is defined as "acquiring objective knowledge of search se-

TABLE 1

TAXONOMY OF LIBRARY SKILLS AND ERRORS

\begin{tabular}{|c|c|}
\hline & Affective Domain \\
\hline $\begin{array}{l}\text { Level } 3 \\
\text { Internalizing } \\
\text { the library }\end{array}$ & \begin{tabular}{l}
\multicolumn{1}{c}{ A3 } \\
\multicolumn{1}{c}{ Affective } \\
Internalization \\
Demonstrating support for \\
the library perspective on \\
society and self. \\
(=Library Conscience and \\
Morality versus Negli- \\
gence)
\end{tabular} \\
\hline
\end{tabular}

A2

Affective

Interaction
Level 2

Interacting with the

Library

Demonstrating continuous striving and value preferences favorable to the library and its system. (=Positive Library Attitudes versus Library Resistance)

\section{A1}

Affective

Orientation

Level 1

Orienting

to the

Library to practice library tasks
Demonstrating willingness and maintaining selective attention.

(=Library Adjustment versus Library Maladjustment)
Cognitive Domain

C3

Cognitive

Internalization

Acquiring personal knowing and subjective intuition of a scholarly discipline.

= Disciplinary Connection versus Lacking Connection)

\section{$\mathrm{C} 2$}

Cognitive

Interaction

Acquiring objective knowing of search sequences, their analysis and synthesis.

(=Library Search Protocol versus Idiosyncratic Search Protocol)

\section{C1}

\section{Cognitive Orientation}

Acquiring representative knowing and comprehending library relevant distinctions.

(=Library Map and Glossary versus Library Ignorance)
Sensorimotor Domain

\section{S3}

Sensorimotor Internalization Performing cumulative searches in one's field and promoting the library in one's life.

(= Lifelong Library Use versus Library Disuse)

\section{S2}

Sensorimotor Interaction

Negotiating search queries and performing a single, one-time search that meets a current information need.

(=Library Proficiency versus Library Ineptitude)

$$
\text { S1 }
$$

Sensorimotor Orientation

Performing physical operations (hands-on experience, browsing and walking around)

(=Library Exploration and Efficiency versus Library Avoidance and Inefficiency) 
quences, their analysis and synthesis (= library search protocol vs. idiosyncratic search protocol)."

The taxonomy provides a theory for developing instructional objectives in the acquisition of information searching competence (ISC). Affective, cognitive, and sensorimotor (ACS) objectives can be constructed for three levels: orienting to the information environment (L1, basic); interacting with it (L2, intermediate); internalizing its features (L3, advanced). Quiz questions can then be constructed to measure a student's feelings, comprehension, and performance. This study was designed to develop a half-hour online measure of a person's current skills profile in the nine categories of information search behavior.

\section{INSTRUCTIONAL OBJECTIVES FOR SEARCHING COMPETENCE}

It was necessary to adapt the taxonomy to the topic of information searching competence by following the definitions for the nine categories of search behavior (as given in table 1). Table 2 is the result. The progression in the affective domain from basic (L1) to advanced (L3) plots the development of a person's struggle to overcome technophobia (general and specific). For example, many students experience a general fear on entering a large library or computer lab. At a basic level, they must learn to overcome this resistance through accepting the ways of the new environment (adjustment) [A1]. However, to ad- vance they must in addition learn to become supportive in specific ways, such as appreciating and desiring to make use of the tools the library provides [A2]. Lastly, users must learn to derive enthusiasm and energy from the perception that they are improving [A3].

The progression in the cognitive domain is marked by first learning how to interpret displays and acquiring necessary terminology ([C1] in table 2); then, learning the classification scheme and how to determine search steps [C2]; finally, acquiring familiarity and intuition about how information is organized in disciplines and how professions disseminate findings [C3]. The progression in the sensorimotor domain from basic skills $([\Sigma \times]$ in table 2$)$ to advanced skills [S3], begins with recognizing the salient information elements of a search problem. This involves learning to modulate the rhythm of visual and motor acts, such as visually focusing on the information fields in an entry, rather than randomly looking around, or walking according to a plan rather than aimlessly [S1]. In the next stage, users must go beyond merely recognizing the literal meaning to identifying the background structure from the foreground elements, such as distinguishing between title of article and title of magazine [S2]. Ultimately library users must learn to incorporate accuracy and standardization in their information recording, becoming regular searchers as they develop into information specialists [S3].

TABLE 2

TAXONOMY OF BEHAVIORAL OBJECTIVES

FOR INFORMATION SEARCHING COMPETENCE (ISC)

\begin{tabular}{|c|c|c|c|}
\hline Levels & Affective Domain & Cognitive Domain & Sensorimotor Domain \\
\hline $\begin{array}{l}\text { Level } 3 \\
\text { Advanced }\end{array}$ & $\begin{array}{c}\mathrm{A} 3 \\
\text { Feeling Empowered }\end{array}$ & $\begin{array}{l}\mathrm{C} 3 \\
\text { Acquiring Familiarity and } \\
\text { Intuition with Disciplines }\end{array}$ & $\begin{array}{l}\text { S3 } \\
\text { Practicing Documentation } \\
\text { Routines }\end{array}$ \\
\hline $\begin{array}{l}\text { Level } 2 \\
\text { Intermediate }\end{array}$ & $\begin{array}{c}\mathrm{A} 2 \\
\text { Being Supportive }\end{array}$ & $\begin{array}{l}\mathrm{C2} \text { Search } \\
\text { Understanding Search } \\
\text { Strategy }\end{array}$ & $\begin{array}{l}\quad \text { S2 } \\
\text { Identifying Implicit Fea- } \\
\text { tures }\end{array}$ \\
\hline $\begin{array}{l}\text { Level } 1 \\
\text { Basic }\end{array}$ & $\frac{\text { A1 }}{\text { Showing Acceptance }}$ & \begin{tabular}{l}
\multicolumn{1}{c}{ C1 } \\
Decoding Information \\
Displays and Terminol- \\
ogy
\end{tabular} & $\begin{array}{l}\text { S1 } \\
\text { Recognizing Information } \\
\text { Elements and Locations }\end{array}$ \\
\hline
\end{tabular}




\section{CONTENT AREAS AND QUESTIONS}

Table 2 was used to help isolate conteni areas that are important to students searching an academic library environment. Quiz items of various types were constructed to represent specific skills in each of the nine categories of search behavior. Table 3 lists the content areas represented in the set of seventy-one questions used in this study. ${ }^{8}$ In the affective domain, the purpose was to sample positive and negative feelings toward some features of the information environment. For example, "I feel that I am bothering the librarian when I ask a question." Yes/No [A1] or, "It is unfair to make people look up things themselves. The librarians should do it for the patrons." Yes/No [A3]. An individual with a low score in this skills category may be struggling with technophobia and can be helped with instructional activities that debunk maladapted attitudes within the information environment.

\section{"Without the affective support, cog- nitive skills are not acquired."}

Some may wonder whether the concept of "skill" applies to the affective as well as the cognitive domains. Traditionally, the cognitive domain was considered primary in educational objectives because it was evident that intellectual activities can be broken into sub-tasks and can be taught sequentially. However, this experience with the cognitive objectives brought the awareness that without the affective support, cognitive skills are not acquired. For instance, librarians can teach and demonstrate the use of particular tools, but this will not promote better searching unless people have positive attitudes about learning to use tools. Scholars used to think that developing such positive attitudes was up to the individual, but now they realize that attitudes are learned skills and can be taught. ${ }^{10}$ Thus, affective skills need to be taught along with cognitive skills to ensure that learning can occur.
In the cognitive domain, the purpose was to sample the steps college students ideally go through when learning to do library research for a required paper. In the current setting this included using an online catalog. For example, an online catalog record was displayed on the screen, and a series of questions were asked about it ("Type the two broadest subject headings of the four listed." [C3], "Which OPAC command should you use to find other books in this series?" [C2] "Would you be able to borrow this book right now?" [C1]). Sampling the students' emerging familiarity with LC classification and academic fields was done through matching, such as this question [C3]:

"Assign the correct call number to each of the following academic fields."
(a) $\mathrm{L}$
(b) $\mathrm{K}$ (c) BF
(d) HM

LAW

EDUCATION

SOCIOLOGY PSYCHOLOGY

Learning to recognize elements of research design in articles by their titles was measured in the following [C3] example:

"Identify the independent variables (IV) and the dependent variables (DV) in each title. Here are two examples:

"The role of intergroup contact in change of prejudice and ethnic relations."

IV = intergroup contact

$\mathrm{DV}=$ change of prejudice and ethinic relations

"Comparative effectiveness of a slide-tape

show and a library tour."

IV = a slide-tape show and a library tour

$\mathrm{DV}=$ comparative effectiveness

Now here is the title:

"Lecture titles written in plain English increase student interest."

IV $=\{$ ANSWER: Lecture titles (written in plain English) $\}$

$\mathrm{DV}=\{\text { ANSWER: student interest }\}^{11}$

In the sensorimotor domain, the purpose was to sample certain perceptual skills, such as identifying information in labeled fields when looking at an OPAC display ("Who is the publisher of this book?'" [S1], " Is Political Threat one of the subject headings?" $[\Sigma \times]$. Another skill sampled was transforming the information from a catalog entry into a bibliographic citation [S3]. 
The content areas in table 3 are not fixed, but reflect the focus of this study. Other content areas should be explored, each with its own pool of questions. Theoretically, an unlimited pool of potential questions exists within each content area and category. The ISC measure is a technique to be adapted to individual situations, rather than a fixed instrument.

Figure 1 portrays an overall perspective on the distribution of instructional objectives for information search behavior. The shaded grid of the cube is the same as the face of table 2. Questions can be constructed for each of the nine categories of search behavior in any number of content areas. For example, Reading Displays had [C1], [S1], and [S2] items. Of course, any content area can be measured in all of the nine categories.

\section{ONLINE QUIZ ENVIRONMENT}

The author selected an online delivery system for making the ISC quiz readily available to users, deciding on the PLATO computer-based education system. ${ }^{12}$ Questions were entered in the quiz format of PLATO's Tutor authoring language. The question forms include multiple choice, matching, yes/no, and fill-in items. Answers typed in are automatically evaluated by PLATO's judging capacity, matching the alternatives supplied for each item. For example, in an item asking the student to identify the month in a periodical index entry, acceptable answers include "February," "Feb," "F," and " 2 ." In the case of writing a citation from a catalog record, punctuation, capitalization, and order were ignored in judging, so that an answer was scored incorrect only for

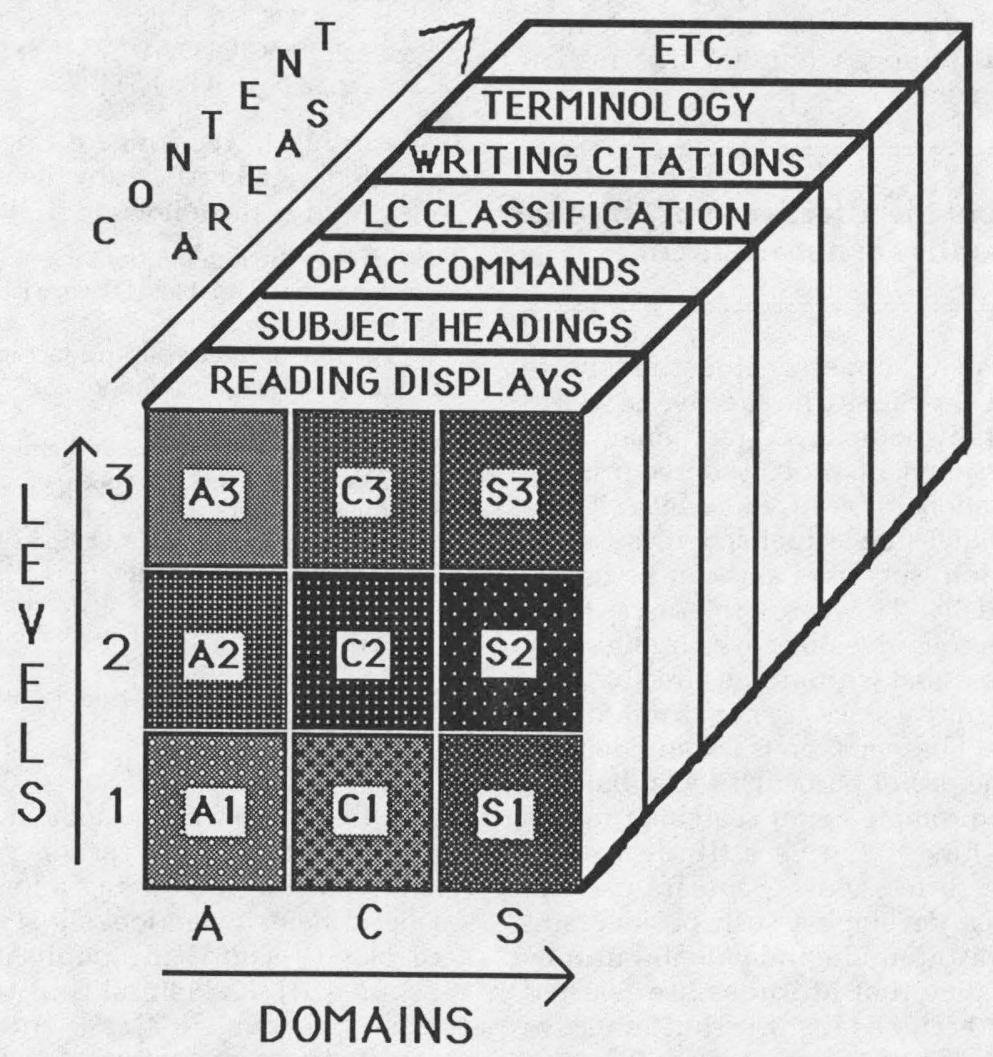

FIGURE 1

The Distribution of Instructional Objectives for Information Search Behavior 
omitting necessary information or for misspelling.

Online statistics are available on the choices selected by each student, and on the total time spent. A printout of the fillin answers is obtainable. each person receives a random presentation of the questions and immediate feedback on the correct answer. At the end of the session the computer displays the number and percentage of correctly answered questions. Students then have a chance to answer an online biographical questionnaire and to add their personal comments.

\section{RESULTS FROM ITEM ANALYSIS}

Table 3 presents the percent correct for each of the seventy-one questions. These item analysis statistics are taken from the PLATO records and are based on approximately 130 scores on the average. This number varies slightly from item to item since the data includes the attempts of people who didn't complete the test, as well as a few trials by the PLATO system operators. Also included are retakes done by some students. These cumulative percentages continually change somewhat but tend to stabilize as more people take the quiz. The highest percentages are obtained for the affective items, regardless of the level. An abnormally low score $(2 \%)$ is posted for the item on writing a citation (S3). The cognitive and sensorimotor scores appear broadly distributed, thus measuring a variety of independent skills. As well, the scores validate the levels, with level 3 items posting lower scores. Exact calculations are presented in table 4 for a subset of scores isolating the three designated student populations.

\section{RESULTS FOR THREE POPULATIONS}

From the perspective of teaching information skills, the students in this study comprise three different population groups: undergraduates, library and information science graduate students (LIS), and international graduate students who did not meet the certification level on the TOEFL. ${ }^{13}$ The expectation was that the overall score on the ISC measure would reflect the differences in information skills among the three populations. Thus, the highest scores should come from LIS students and the lowest scores from international graduate students. The undergraduates should produce scores in between. The subjects took the online quiz in the computer lab at their own convenience. No time limit was imposed, but they were told that the quiz takes less than an hour to complete.

The results are presented in table 4 . The average time to complete the online quiz was thirty-four minutes. The differences among the three samples are in the expected direction and are statistically highly significant. The undergraduates' familiarity with the PLATO system might account for their faster completion time.

In terms of percent correct, the three groups performed as expected, with a mean of $74 \%$ for the library students, $59 \%$ for the undergraduates, and $49 \%$ for the internationals. Statistically, this is a highly significant effect despite the small samples. The sub-scores corroborate the intended manipulation of three levels of development. The questions in the basic level averaged out at $73 \%$, intermediate level questions at $53 \%$ and advanced, at $45 \%$. This pattern was confirmed for each of the three groups. Also, the expected difference among the three populations is replicated at each level to a highly statistically significant degree.

"The concept of affective library search errors recognizes that users' freedom of access to information is restricted by irrational fears or unreasonable frustrations."

\section{RESEARCH ISSUES}

The concept of affective library search errors recognizes that users' freedom of access to information is restricted by irrational fears or unreasonable frustrations. These fears are evident in user selfreports, as in the following samples:

I was totally lost when I first walked into Hamilton. 
TABLE 3

DISTRIBUTION AND ANALYSIS OF ITEMS

\begin{tabular}{|c|c|c|}
\hline Content Areas and Abbreviated Questions & $\begin{array}{l}\text { Catego } \\
\text { of Skill }\end{array}$ & $\begin{array}{l}\% \\
\text { Correct }\end{array}$ \\
\hline Affective Domain (nine questions) & & \\
\hline $\begin{array}{l}\text { Service and Facilities }(7) \\
\text { I appreciate floorplan maps. }\end{array}$ & & \\
\hline I feel I'm bothering the librarian. & $\begin{array}{l}\text { [A1] } \\
\text { [A1] }\end{array}$ & $\begin{array}{l}98 \\
84\end{array}$ \\
\hline I like using computers for searching. & [A2] & 94 \\
\hline $\begin{array}{l}\text { Is it o.k. to ask about phone numbers? } \\
\text { Unfair to have people look things up. }\end{array}$ & {$[\mathrm{A} 2]$} & 83 \\
\hline Glad library has online computer. & [A3] & 92 \\
\hline People learn by looking things up. & [A3] & 92 \\
\hline Disciplines and Areas (1) & & \\
\hline There are too many fields of study. & [A2] & 90 \\
\hline Reading Displays (1) & & \\
\hline OPAC displays are useful, well organized. & [A2] & 94 \\
\hline $\begin{array}{l}\text { Cognitive Domain: ( } 45 \text { questions) } \\
\text { Reading Displays ( } 2 \text { ) }\end{array}$ & & \\
\hline Is this book available at Sinclair Library? & [C1] & \\
\hline Can this book be borrowed right now? & [C1] & 82 \\
\hline Subject Headings ( 3 ) & & \\
\hline What's the main subject heading? & [C1] & 76 \\
\hline To find more on this topic, which subject heading is best? & [C2] & 58 \\
\hline $\begin{array}{l}\text { Which are the two broadest subject headings? } \\
\text { OPAC COMMANDS (4) }\end{array}$ & [C3] & 28 \\
\hline To find another book on the same topic, which command is best? & {$[\mathrm{C} 2]$} & 41 \\
\hline To find other books in this series, which & & \\
\hline command is best? & [C2] & 36 \\
\hline What will happen on this screen if you press ENTER? & [C2] & 38 \\
\hline $\begin{array}{l}\text { When you know title but not author, which } \\
\text { command is best to get call number? }\end{array}$ & {$\left[\mathrm{C}_{2}\right]$} & 81 \\
\hline LC Classification (12) & & \\
\hline What is call number area for these fields? & [C2] & 58 \\
\hline Search Strategy (3) & & \\
\hline Which alternative is best to find a journal article on this topic? & [C2] & 49 \\
\hline Which alternative is best to find this book with this call number? & [C2] & 63 \\
\hline Which strategy alternative is wrong? & [C2] & 41 \\
\hline Terminology (6) & & \\
\hline Select the correct definition for terms. & [C1] & 73 \\
\hline Locations (4) & & \\
\hline $\begin{array}{l}\text { Select the correct location for these materials. } \\
\text { Disciplines and Areas (5) }\end{array}$ & [C1] & 68 \\
\hline $\begin{array}{l}\text { Disciplines and Areas (5) } \\
\text { Match fields of study with major areas of study. }\end{array}$ & [C3] & 81 \\
\hline $\begin{array}{l}\text { Research Methods in Titles (6) } \\
\text { Identify the independent and dependent variables for these titles. }\end{array}$ & & \\
\hline Identify the independent and dependent variables for these titles. & [C3] & 40 \\
\hline $\begin{array}{l}\text { Sensorimotor Domain: (17 questions) } \\
\text { Reading Displays ( } 8 \text { ) }\end{array}$ & & \\
\hline Who is the publisher of this book? & & 69 \\
\hline Where was this book published? & [S1] & 40 \\
\hline Is there an index in this book? & [S1] & 90 \\
\hline Is "Political Threat" one of the subject headings? & [S1] & 93 \\
\hline In which month was this article published? & [S1] & 74 \\
\hline Is this article illustrated? & [S2] & 86 \\
\hline What's the magazine title? & [S2] & 69 \\
\hline What's the title of the article? & [S2] & 83 \\
\hline Writing Citations (1) & & \\
\hline Write a citation from this catalog entry. & [S3] & 2 \\
\hline $\begin{array}{l}\text { Reproducing Titles (6) } \\
\text { Try to remember these }\end{array}$ & & \\
\hline $\begin{array}{l}\text { Try to remember these } \\
\text { Call Number Ranges (2) }\end{array}$ & [S3] & 23 \\
\hline Select the shelf range that includes this call number. & [S1] & 62 \\
\hline
\end{tabular}


TABLE 4

PERCENT CORRECT ON THE ISC QUIZ FOR THREE POPULATIONS

\begin{tabular}{|c|c|c|c|c|c|c|c|c|c|}
\hline Groups & $\mathrm{N}$ & $\begin{array}{c}\text { Time } \\
\text { (mins.) }\end{array}$ & Total & 1 & $\begin{array}{l}\text { Levels } \\
2\end{array}$ & 3 & A & $\begin{array}{c}\text { Domains } \\
\text { C }\end{array}$ & $\mathrm{s}$ \\
\hline LIS Student & 11 & 35 & 74 & 89 & 81 & 56 & 92 & 75 & 60 \\
\hline $\begin{array}{l}\text { Undergraduates } \\
\text { International }\end{array}$ & 43 & 2 & & 72 & & 4 & 90 & & 48 \\
\hline Grad Students & 15 & 47 & 4 & 63 & 4 & 37 & 85 & 48 & 33 \\
\hline Combined & 69 & 34 & 59 & 73 & 53 & 45 & 88 & 53 & 42 \\
\hline $\begin{array}{l}\text { Anova: } F(2,66)= \\
\text { Significance level }\end{array}$ & & $\begin{array}{l}24.4 \\
.0001\end{array}$ & $\begin{array}{l}27.8 \\
.0001\end{array}$ & $\begin{array}{l}11.8 \\
.0001\end{array}$ & $\begin{array}{l}23.6 \\
.0001\end{array}$ & $\begin{array}{l}9.0 \\
.0004\end{array}$ & $\begin{array}{l}1.4 \\
.2613\end{array}$ & $\begin{array}{l}24.4 \\
.0001\end{array}$ & $\begin{array}{l}15.3 \\
.0001\end{array}$ \\
\hline Number of Questions & & & 71 & 23 & 22 & 26 & 9 & 45 & 17 \\
\hline
\end{tabular}

I can tell you that I had great apprehensions at the thought of having to do a library research paper.

It shocked me to visit a library with five floors compared with one floor, and I felt that I was in another world.

Two weeks ago I walked into the library lost and confused.

Here is another description of the hectic time I spent looking for information on diet.

I was frustrated when many of the articles that I looked up in the indexes were in magazines not carried at the library.

The most frustrating thing was trying to look for articles in the indexes.

Walking around the library with a dazed and confused look on my face wasn't unusual.

The implication of this evidence is that library services need to take explicitly into account the affective behavior of users as well as their cognitive strategies and sensorimotor actions.

Tests of library skills generally have focused on the cognitive domain. Where affective as well as cognitive skills are measured, the practice seems to be to obtain separate scores for each domain. ${ }^{14} \mathrm{~A}$ combined score, where two or all three domains are included, as in this study, reflects the integrated nature of human behavior. While there are three discreet domains of behavior, the three integrate in human interaction. As table 4 shows, the percent correct is reported for each domain as well as the combined total percent correct. Since it is the affective that makes the cognitive alternatives available, people with a negative affective direction hinder their ability to learn search strategies. Research and practice will indicate the types of feedback that are best for affective items, as distinguished from feedback for cognitive or sensorimotor items. Scoring the items in all three domains as correct or incorrect and obtaining a total score reflects the theoretical and methodological properties of the behavioral taxonomy. Future studies will explore the relationship between cognitive and affective scores. In this study all of the intercorrelations among the nine categories were too low to reach statistical significance.

In future studies, a greater variety of affective items will be used. The current items appear to be too general, with average scores above 85 percent (see table 4 ). Affective items of the following kind illustrate other directions for testing this domain:

Libraries should be small. YES/NO [A2]

When I have to go to the library I put it off as long as I can.

APPLIES TO ME/DOES NOT APPLY TO ME [A1]

When I'm doing research for a paper, I feel that I am wasting a lot of my time.

APPLIES TO ME FREQUENTLY/APPLIES TO

ME SOMETIMES [A1]

When I'm doing research for an assignment, I'm grateful that the library is well organized.

$Y$ ES/NO [A2]

When I leave the library, I feel that my intellect is expanded.

SOMETIMES/NEVER [A3]

Learning how to find information will help me in my future career.

DEFINITELY APPLIES TO ME/DOES NOT APPLY TO ME [A3]

I like being in the library. ALMOST ALWAYS/ALMOST NEVER [A3]

I love libraries.

ALMOST ALWAYS/ALMOST NEVER [A3] 
The atmosphere in the library is peaceful ALMOST ALWAYS/ALMOST NEVER [A3]

The library is too big and impersonal. ALMOST ALWAYS/ALMOST NEVER [A3]

The library is too frustrating. ALMOST ALWAYS/ALMOST NEVER [A1]

I don't like using OPAC. $Y E S / N O$ [A2]

I have to improve on using OPAC. $Y$ ES/NO [A2]

I need to improve my library research skills. $Y E S / N O$ [A2]

I feel I should be using libraries more. $Y$ ES/NO [A2]

I am frequently embarrassed to ask a librarian a question when I should already know the answer.

\section{TRUE/FALSE [A1]}

The library is the heart of the academic and scientific community.

AGREE/DISAGREE [A3]

Library research should not be required to get a bachelor's degree.

AGREE/DISAGREE [A1]

Libraries are wonderful and fun. AGREE/DISAGREE [A3]

It is important to continue to use libraries after graduation.

\section{AGREE/DISAGREE [A2]}

Is not appropriate to ask the librarian how to find information on personal problems?

$$
Y E S / N O \text { [A1] }
$$

It is exciting to find needed information.

$$
Y E S / N O \text { [A3] }
$$

It is not important to continue to learn new ways of searching for information throughout life.

\section{AGREE/DISAGREE [A2]}

Whether or not I find what I need in the library depends more on how much the library has on my topic than on my own research skills.

$A G R E E / D I S A G R E E$ [A2]

To a great extent finding information that I need is controlled more by chance than by systematic searching.

TRUE/FALSE [A2]

I can pretty much find on my own whatever I need in the library.

$Y E S / N O$ [A3]

I hate it when I have to look up the same subject heading in several annual volumes of a periodical index.

$Y E S / N O$ [A1]

They should go back to card catalogs instead of computers.

AGREE/DISAGREE [A2]

I don't like looking for call numbers because the books are hardly ever there.

TRUE/FALSE [A1]
These items reflect student comments made in a special Library Research Journal section of their term papers. Each item represents an affective skill or error depending on which direction the person is moving. Assuming the person is answering the questions objectively, as a selfwitness, the item identifies some particular adaptive or maladaptive habit in the affective domain. For instance, persons answering "Applies to $\mathrm{me}^{\text {" }}$ to the item "When I have to go to the library I put it off as long as I can," indicates a tendency to circumvent instructions and the learning steps they must go through to acquire information searching competence. It is to be expected that such feelings of resistance occur in clusters and begin to interfere actively with the acquisition of cognitive and sensorimotor skills. In the behavioral sense they are affective errors or impediments to skill acquisition.

\section{"Bibliographic instruction can help address affective errors or impedi- ments to skill acquisition in many searches.'}

Bibliographic instruction can help address this need in many searchers. ${ }^{15}$ To alert students to the pervasiveness of this maladaptive syndrome in learning search behavior, the authors have presented students with lists of affective errors and discussed their causes and solutions. To make students more specifically aware, they had to read the Library Research Journals of previous students and were given the opportunity to discuss research strategy in small groups. They were also teamed in pairs who met in the library to do research together. These motivational techniques were effective in reducing the strength of maladaptive affective habits as is evident from the student reports. Here are some examples:

Since I have become more familiar with the library through this assignment, my attitude toward research is not negative. Struggling 
through the paper has given me confidence to do more papers.

Now when I walk into the library the surroundings are familiar and I do not feel threatened or lost. The assignment broadened my ability as well as my awareness of what the library has to offer, not only scholastically just for pleasure.

I discovered how to make the library work for me. I now know how to use most of the library system including the help of the reference librarians.

The process of gathering information was an enriching lesson that can be utilized for years to come.

I enjoyed the trips to the libraries and found it educational. Now I know where to get information that I need.

As can be seen from these comments, apprehension and avoidance were replaced by enthusiasm and gratitude, and a feeling of empowerment in having acquired a tool that can be used again and again. Thus, maladaptive affective errors are replaced by adaptive affective skills in information searching.

An additional research issue concerns the online environment of the quiz and the effect of prior experience with computers. The online environment could be contrasted with a control such as a written version, in order to assess the effect of typing errors, using function keys, screen displays, and the controlled sequencing of items. Another control consists in using a different online environment such as Hyper Card, a more visually oriented userfriendly system. ${ }^{16}$

Research will show the extent to which the ISC measure can be used for diagnostic purposes. Test/retest reliability needs to be established. A small sample of undergraduates who took the quiz again within three weeks improved their scores by nine percent. This modest, but statistically significant gain occurred even though students did not received any bibliographic instruction. The increase could be attributed to the test's instructional feature of giving immediate feedback for each item. The test/re-test correlation was .78 $(\mathrm{N}=27)$, showing the answers to be quite stable. Pre-post test studies in an instructional context ought to be done to deter- mine the sensitivity to change in competence as a result of an instructional intervention or other learning experience. As well, the predictive value of the total ISC score needs to be explored. Is it indicative of a person's on-the-job performance, or success in making use of information tools?

\section{THE STRUCTURE OF THE ACS INFORMATION UNIT}

Figure 2 is a three-dimensional view of table 2 . The shaded rectangles in figure 2 correspond to the face of table 2 . It can be seen that each of the nine categories of skills is made up of all three domains. In this study, only one of the three domains was selected for each of the nine categories, though it would be possible to construct a quiz that samples all three domains for each item. Behavior theory requires the integration of all three domains in every act (the ACS unit). How is it possible to have separate instructional objectives for each domain? Teaching requires a single-minded focus and leads to the selection of one of the three domains

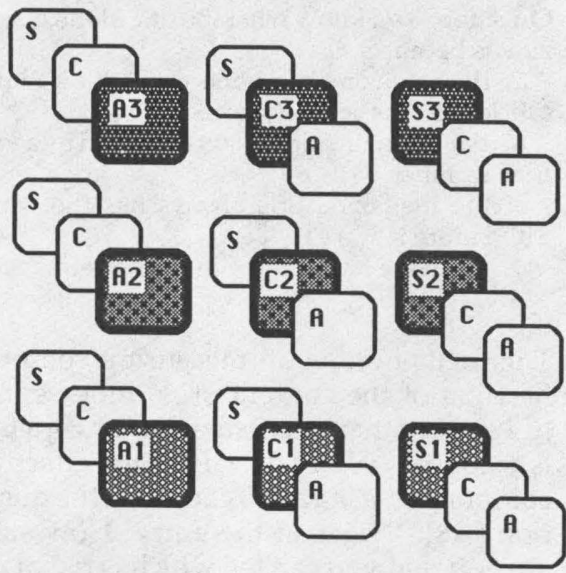

KEY

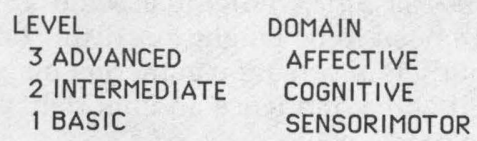

FIGURE 2

The Structure of the ACS Information Unit 
of the ACS unit to be measured by a single item. For instance one question used for category [S2] is:

\author{
Computers \\ see also \\ Artificial intelligence \\ Microprocessors \\ Psychological Uses \\ My fair software. J. Gorman. il Discover 6:64-5 \\ $F^{\prime} 85$
}

Question: What is the title of the magazine in which this article is published?

ANSWER: Discover

The instructional focus here is on the sensorimotor skill involved in perceiving the distinction between magazine title and article title and then typing the title accurately-an item that had a 30 percent error rate. To focus on the cognitive component that relates to this sensorimotor skill, the librarian could construct the following item [C2].

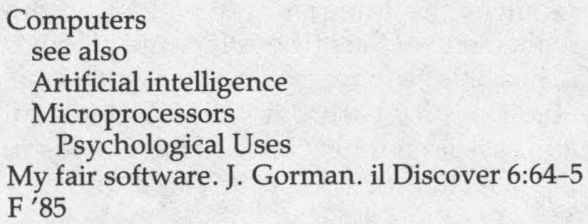

Question: You know what the title of the magazine is because:

a. the magazine has a one-word title and the article title has several words.

b. the magazine title is accompanied by a volume number

c. the magazine title always has the word "il" before it

d. software has to do with computers

ANSWER: $\mathrm{b}$

The focus here is on measuring comprehension of the content of an index entry [C2] rather than recognizing it or copying is accurately [S2]. To focus on the affective component, a librarian could ask the question [A2]: "Look at the entry. How sure are you that you can tell which is the magazine title and which is the article title?" Sure/Not Sure. Individuals who are not sure need to be taught this distinction so that their information gathering may proceed with confidence-an important affective search skill.

\section{MEASURING THE HUMAN CAPACITY TO SEARCH FOR INFORMATION}

Inspection of the seventy-one questions revealed an interesting relation between the form of the question and the behavioral domain. For instance, the affective questions are all bi-polar (Yes/No, Agree/Disagree), the cognitive questions are multiple-choice and matching forms, and the sensorimotor questions are all fillin type. Human capacity is defined as a rational neurosystem structured into three domains of experience arranged in a topdown control hierarchy. The schema in figure 3 shows the relation between the structure of the domain and the corresponding type of measure. The affective domain on the left is defined as the top of the control hierarchy. ${ }^{17}$ It corresponds to the bi-polar affective system governing the will or the motivation. This has a directional function in all behavior and serves to prioritize goals and to define success. A person with a need for information and the desire to look for it must obtain relevant rather than irrelevant answers. This requires a two-valued logic. Users may have a supportive attitude towards the information environment, or not. As well, they can be supportive in varying degrees. Items measuring the affective component of information searching behavior are bipolar: Yes/No, Agree/Disagree, or a semantic differential scale like "importantunimportant" or "pleasant-unpleasant" with any number of degrees in between.

The affective feeds into the cognitive system's representational function, encoding relevant features of a situation and mapping search strategies under the control of the affective system as each alternative is accepted or rejected. Multiple choice and matching questions are well suited to represent successful and unsuccessful alternatives (scenarios) in decision making. The affective and the cognitive systems jointly feed into the sensorimotor system that has an operational function, noting and performing. Fill-in questions are well suited for this performative func- 
tion as they require the person to perceive selected features and accurately encode them in a fixed order.

In keeping with the basic ACS information unit, it is to be noted that a sensorimotor fill-in item has associated with it both a cognitive and an affective component (see figure 2), though these are not necessarily measured. For example, a [C1] question is:

Select the correct definition for CROSS REFERENCE.

a. A publication that is issued recurrently at specific times under the same title.

b. A scientific, technical, scholarly, or professional periodical.

c. An oversized publication shelved in separate, larger stacks.

d. Broader, narrower, or related terms used to describe topics or subject headings.

ANSWER: d

The instructional focus here is to measure basic cognitive skills relating to the concept of cross-reference. This involves cognitive memory and comprehension of groups of interrelated vocabulary. The correct answer depends on this cognitive activity much more crucially than the sensorimotor skill of typing the letter " $d$, " or the affective skill of desiring to recall what one knows about it. Thus, the affective and sensorimotor components for this cognitive item would ordinarily not be measured.

Suppose one constructed a fill-in item for defining this term: "Type in the definition for CROSS-REFERENCE." Since

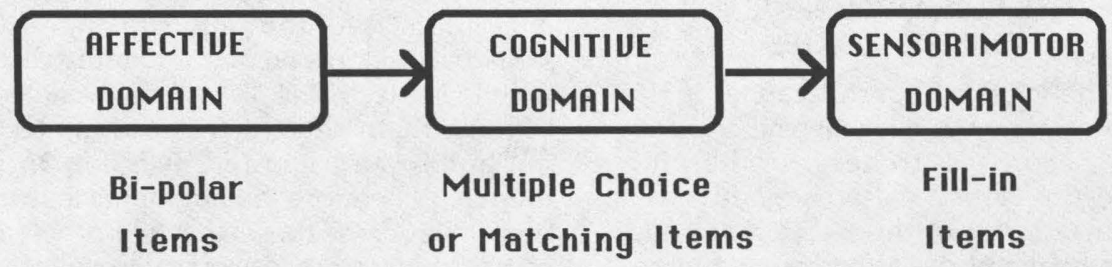

Choosing positive response
Figuring out correct alternative
Writing standard format
DIRECTIONAL

System
REPRESENTATIONAL

System
OPERATIONAL

System
Having a need for relevant information

\& a desire to get it

Being motivated to overcome technophobia
Designing a search strategy with

ranked alternatives

Analyzing problems
8 memorizing
solutions

fnalyzing problems

solutions
Coordinating the execution of search acts

Developing efficiency with search technologies

FIGURE 3

Type of Quiz Item and Behavioral Domain 
this uses the question format for sensorimotor items (see figure 3), the answer depends on sensorimotor memory, rather than cognitive as in the previous format for this item. This sensorimotor memory depends on prior experience with writing down and reading definitions of crossreference. Thus, a person unable to write out a definition for CROSS-REFERENCE may be able to reason out the correct definition from a set of alternatives.

The most difficult question was the sensorimotor item asking students to type a bibliographic citation from a catalog entry [S3]. Error analysis showed that part of the problem for many people was having to type an answer as long as two lines, and another part was knowing which information to select from the catalog entry displayed. These two components should be measured separately, using items appropriate to each.

\section{THE LIBRARY USER'S THREE MEMORIES}

The instructional significance of the ACS information unit is that teaching people to become searchers, or helping searchers to be better searchers, involves the management of three different types of human memory-affective, cognitive, and sensorimotor. Affective memory is required for acquiring affective information skills, just as cognitive memory is required for learning cognitive information skills. The same is true for sensorimotor memory. Advances in research and practice will reveal the characteristics of each memory and how these may be applied to curriculum design. ${ }^{18}$ In general, sensorimotor memory is built up by hands-on practice; cognitive memory is built up by exploration of alternatives to a specified

\section{"The widespread practice of focus- ing almost exclusively on cognitive skills relies on the individual's own initiative to supply the affective and to keep up with the sensorimotor."}

situation; affective memory is built up through social exchanges and through successes.

The wide spread practice of focusing almost exclusively on cognitive skills relies on the individual's own initiative to supply the affective and to keep up with the sensorimotor. However, as the information environment becomes more complex, a greater percentage of the population is cut off from normal interaction with standard information tools. This is due to automation and the proliferation of reference tools. ${ }^{19}$ As the requisite cognitive skills become more complex, individuals with low affective skills will not be able to acquire them due to frustration, technophobia, and learned aversion to libraries. ${ }^{20}$ Therefore, bibliographic instruction can address these affective problems by teaching users those affective skills that will permit them to acquire the complex cognitive skills. This is not a matter of psychotherapy, rather it is the recognition by the information specialist that effective search behavior includes affective skills. These must be dealt with in bibliographic instruction by developing appropriate instructional objectives in the affective domain, including them in the curriculum and in library skills tests. ${ }^{21}$ The ACS unit can be used as a model for developing these instructional objectives.

\section{REFERENCES AND NOTES}

1. Dennis Hamilton, "Library Users and Online Systems: Suggested Objectives for Library Instruction," RQ 25:195-97 (Winter 1985); " Model Statement of Objectives for Academic Bibliographic Instruction: Draft Revision," College \& Research Libraries 48:256-60 (May 1987).

2. Benjamin S. Bloom, ed., Taxonomy of Educational Objectives: The Classification of Educational Goals: Handbook I: Cognitive Domain (New York: David McKay, 1956) passim; David R. Krathwohl, Benjamin S. Bloom, and Bertram B. Masia, Taxonomy of Educational Objectives: The Classification of Educational Goals: Handbook II: Affective Domain (New York: David McKay, 1964) passim; Walter D. Pierce and Charles E. Gray, Deciphering the Learning Domains: A Second Generation Classification 
Model for Educational Objectives (Washington, D.C.: Univ. Press of America, 1979) passim.

3. Karen Ponish, "'Babywise' and Toys Develop Literacy Skills," American Libraries 18:709-10 (Sept. 1987).

4. James Rice, Jr., Teaching Library Use: A Guide for Library Instruction (Westport, Conn.: Greenwood, 1981), p.42.

5. Carol Collier Kuhlthau, "Feelings in the Library Research Process," Arkansas Libraries 42:23-26 (June 1985).

6. Carol Wright and Mary Ellen Larson, "Basic Information Access Skills: Curriculum Design Using a Matrix Approach" College \& Research Libraries (submitted 1989).

7. Leon A. Jakobovits and Diane Nahl-Jakobovits, "Learning the Library: Taxonomy of Skills and Errors," College \& Research Libraries 48:203-14 (May 1987).

8. The set of 71 questions is available on request from the authors.

9. Diane Nahl-Jakobovits and Leon A. Jakobovits, "Managing the Affective Micro-Information Environment," Research Strategies 3, no.1:17-28 (Winter 1985).

10. Charles E. Osgood, George Suci, and Percy H. Tannenbaum, The Measurement of Meaning (Urbana, Ill.: Univ. of Illinois Pr., 1957).

11. Diane Nahl-Jakobovits and Leon A. Jakobovits, "Teaching the Analysis of Titles: Dependent and Independent Variables in Research Articles," Research Strategies 5:164-71 (Fall 1987).

12. PLATO is a national computer network developed at the University of Illinois in the 1960s for the delivery of general education lessons to schools and homes. PLATO terminals are available in the computer lab located in the Library. PLATO has a catalog of hundreds of interactive lessons in most academic subjects. Instructors may input their own lessons, quizzes, tests, and messages. Students use the terminals on their own time by signing-on with their password.

Donald L. Bitzer, "The PLATO Project at the University of Illinois," Engineering Education 77:175-80 (1986); Elisabeth R. Lyman, PLATO Highlights 7th ed. (Urbana: University of Illinois, 1981). The quiz was entered with assistance from David Lassner and Sue Larsen of the University of Hawaii Computing Center.

13. TOEFL: Test of English as a Foreign Language (Princeton, N.J.: Educational Testing Service, 1988).

14. Virginia Tiefel, "Evaluating a Library User Education Program: A Decade of Experience," College E Research Libraries 50:249-59 (March 1989).

15. Nahl-Jakobovits, "Managing the Affective," passim.

16. Dan Shafer, HyperTalk Programming (Indianapolis, Ind.: Hayden Books, 1988); Mimi Jones and Dave Myers, Hands-on HyperCard: Designing Your Own Applications (New York: John Wiley, 1988).

17. The foundations of rational neuroscience are found in the writings of Emmanuel Swedenborg. "In every complete thing there is a trine which is called First, Mediate, and Ultimate, also End, Cause, and Effect." He identifies the trine of human behavior as the affective ("loves" and "affections"), and the cognitive ("thoughts," "reflections," and "understanding"), and sensorimotor ("actions" and "sensations"). Actions and sensations are thus effects of thought propelled by loves. True Christian Religion (New York: Swedenborg Foundation, 1981 [1771]), no. 210; "Affection, thought, and action are also in a series of like degrees, because all affection has relation to love, thought to wisdom, and action to use." Angelic Wisdom Concerning the Divine Love and the Divine Wisdom (New York: Swedenborg Foundation, 1976 [1763]), no. 214.

18. Carol Tenopir, Diane Nahl-Jakobovits, and Dara Lee Howard, "Magazines Online: Users and Uses of Full Text," ASIS '89 Proceedings 26:173-75 (October 1989); Carol Tenopir, Diane NahlJakobovits, and Dara Lee Howard, "Full Text Search Strategies and Modifications: The Role of the Searcher and the Role of the System," National Online Meeting 1990 (in press May 1990).

19. ". . . All members of the academic community are likely to become increasingly dependent on skilled professional guidance in the acquisition and use of library resources as the forms and numbers of these resources multiply, scholarly publications appear in more languages, bibliographical systems become more complicated, and library technology grows increasingly sophisticated. The librarian who provides such guidance plays a major role in the learning process." From the "Joint Statement on Faculty Status of College and University Librarians" of the AAUP, Association of American Colleges, and ACRL. Quoted in Ruth W. Clinefelter and Jack E. Hibbs, "The Neglected Information Specialist," Academe 75:29 (July-Aug. 1989).

20. "The library anxiety described by students is similar to that described in the literature on math and test anxiety." Constance Mellon, "Attitudes: The Forgotten Dimension in Library Instruction," Library Journal (Sept. 1, 1988), p.139; Bobbie L. Collins, Constance A. Mellon, and Sally B. Young, "The Needs and Feelings of Beginning Researchers," in Bibliographic Instruction: The Second Generation, ed. Constance A. Mellon (Littleton, Col.: Libraries Unlimited, 1987), p.73-84; Constance A. Mellon, "Library Anxiety in College Students: A Grounded Theory and Its Development," Col- 
lege \& Research Libraries 47:160-65 (March 1986); See also: " . . . unless we are careful, users could become increasingly suspicious of the technology while becoming more dependent on it." Grant Noble and Steve O'Connor, "Attitudes Toward Technology as Predictors of Online Catalog Usage," College \& Research Libraries 47:610 (Nov. 1986); "The micro-information environment encompasses two interdependent domains of inner behavior: the voluntary or affective skills and the intellectual or cognitive skills. The affective micro-environment needs must be managed along with the intellectual needs." Nahl-Jakobovits, "Managing the Affective," p.17.

21. Experience with undergraduate students in a large academic library revealed these facts, as enumerated in their library research journals. They resisted the use of formal aids, such as floor plans and fields in OPAC displays, preferring to follow hunches, guesses, and hopes, rather than be systematic. Research needs to determine the pervasiveness of these affective errors.

"When we wanted to improve our serials management, Faxon responded with DataLinx. We needed journal availability information, quickly. They gave us online access to other libraries' check-in records.

\section{When Faxon responds, the whole subscriber community benefits.}

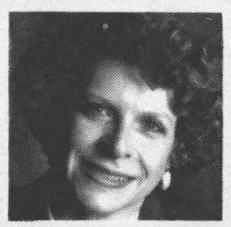

Faxon has belped us through competitive pricing policies and global access to publications. Now they're enhancing relations in the broader subscriber/publisher community by advancing common data communication standards and promoting shared resources. In this sense I see them as colleagues."

-ELLEN J. WAItE, University LibraRian, LOyOLA University of ChiCAGo

Helping you manage your world of information.

To learn more about the Faxon Company, the international subscription agency with a commitment to quality service, call1 (800) 766-0039. 